\section{Slik Sterile-20 kinase regulates Moesin activity to promote epithelial integrity during tissue growth}

\author{
David R. Hipfner, Nadine Keller, and \\ Stephen M. Cohen ${ }^{1}$
}

European Molecular Biology Laboratory, 69117 Heidelberg, Germany

The Drosophila Sterile-20 kinase Slik promotes tissue growth during development by stimulating cell proliferation and by preventing apoptosis. Proliferation within an epithelial sheet requires dynamic control of cellular architecture. Epithelial integrity fails in slik mutant imaginal discs. Cells leave the epithelium and undergo apoptosis. The abnormal behavior of slik mutant cells is due to failure to phosphorylate and activate Moesin, which leads to excess Rho1 activity. This is distinct from Slik's effects on cell proliferation, which are mediated by Raf. Thus Slik acts via distinct pathways to coordinate cell proliferation with epithelial cell behavior during tissue growth.

Supplemental material is available at http://www.genesdev.org.

Received March 22, 2004; revised version accepted July 20, 2004.

Control of tissue growth requires coordination of the rates of cell growth, proliferation, and cell death. Studies in Drosophila and other organisms have demonstrated that proteins involved in cell adhesion and apical-basal polarity also regulate cell proliferation and survival (Gateff 1978; Woods and Bryant 1989; Huang and Ingber 1999; Bilder et al. 2000; Humbert et al. 2003; Zahir and Weaver 2004). Many proteins implicated in cellular transformation, including small GTPases of the Rho family, regulate actin dynamics (Lozano et al. 2003). This indicates that appropriate cellular and tissue architecture is critical for proper regulation of tissue growth. Sterile20 (Ste20) kinases have been implicated in numerous processes, including cytoskeletal regulation (Dan et al. 2001). The Drosophila Slik and Hippo Ste20 kinases regulate cell proliferation, cell survival, and tissue growth. Hippo acts together with Salvador and Warts to suppress growth and promote apoptosis (Harvey et al. 2003; Pantalacci et al. 2003; Udan et al. 2003; Wu et al. 2003). Slik has the opposite effect, promoting growth by accelerating cell proliferation in a Raf-dependent man-

[Keywords: Slik; Ste20 kinase; Moesin; epithelial integrity; apoptosis; actin cytoskeleton]

${ }^{1}$ Corresponding author.

E-MAIL cohen@embl.de; FAX 49-6221-387166.

Article and publication are at http://www.genesdev.org/cgi/doi/10.1101/ gad.303304. ner. Cells lacking Slik have an intrinsic survival defect and undergo apoptosis (Hipfner and Cohen 2003).

Here, we report that Slik acts on cytoskeletal organization by regulating the ERM (ezrin/radixin/moesin) protein Moesin. ERM proteins connect the cortical actin cytoskeleton to the cell membrane. The N-terminal FERM (protein 4.1, ERM) domain of these proteins binds to membrane proteins directly or through adaptor proteins (Serrador et al. 1997; Heiska et al. 1998; Reczek and Bretscher 1998; Yonemura et al. 1998; Yun et al. 1998; Denker et al. 2000). The C terminus contains a conserved actin-binding domain (Turunen et al. 1994). Intramolecular interaction between the FERM and C-terminal domains blocks the membrane protein and actinbinding sites to produce an inactive conformation (Gary and Bretscher 1995; Reczek and Bretscher 1998). Phosphorylation of a conserved threonine residue in the Cterminal domain causes a conformational change that exposes both sites, activating the protein (Matsui et al. 1998).

ERM-mediated linkage of actin to membrane proteins is important for determining cell shape and is required for proper organization of apical membrane structures such as microvilli (Takeuchi et al. 1994). Functional redundancy between Ezrin, Radixin, and Moesin has complicated the genetic analysis of ERM proteins in mammals (Takeuchi et al. 1994; Doi et al. 1999). Moesin is the only Drosophila ERM protein, and mutants lacking Moesin have defects in epithelial organization (Polesello et al. 2002; Speck et al. 2003). moesin mutant cells in the wing imaginal disc lose apical-basal polarity and are extruded from the basal surface of the epithelium. This results in the formation of multilayered rather than monolayered epithelia. All defects are associated with depletion of apical filamentous F-actin and accumulation of F-actin foci and result from overactivation of Rho1 (Speck et al. 2003). We present evidence that Slik regulates Moesin and thereby controls Rho activity. Slikdependent activation of Moesin is required in proliferating epithelial cells to maintain epithelial integrity and thus cell survival, and is also important for differentiation of actin-based structures in postmitotic cells.

\section{Results and Discussion}

\section{Epithelial integrity and cell survival}

The wing imaginal disc is an epithelial sac composed of two distinct but continuous epithelial layers enclosing a central lumen. The portion of the disc that will form the wing is a pseudostratified columnar epithelium. In optical cross-section, the dense packing of the cells is visible, with nuclei appearing stacked in layers (Fig. 1A). Overlying the columnar epithelium is the squamous peripodial epithelium. The apical surface of both epithelial layers is oriented toward the lumen of the disc, as seen by the concentration of F-actin near the adherens junctions (Fig. 1A,E). In wing discs lacking Slik activity, the columnar epithelium was abnormally thin (Fig. 1B). Many cells lost their capacity to remain integrated in the epithelium and were extruded basally to form a disorganized mass (Fig. 1B). Many of these cells underwent apoptosis as evidenced by pyknotic nuclei and by TUNEL labeling, though clusters of cells survived (Fig. 1B, ar- 

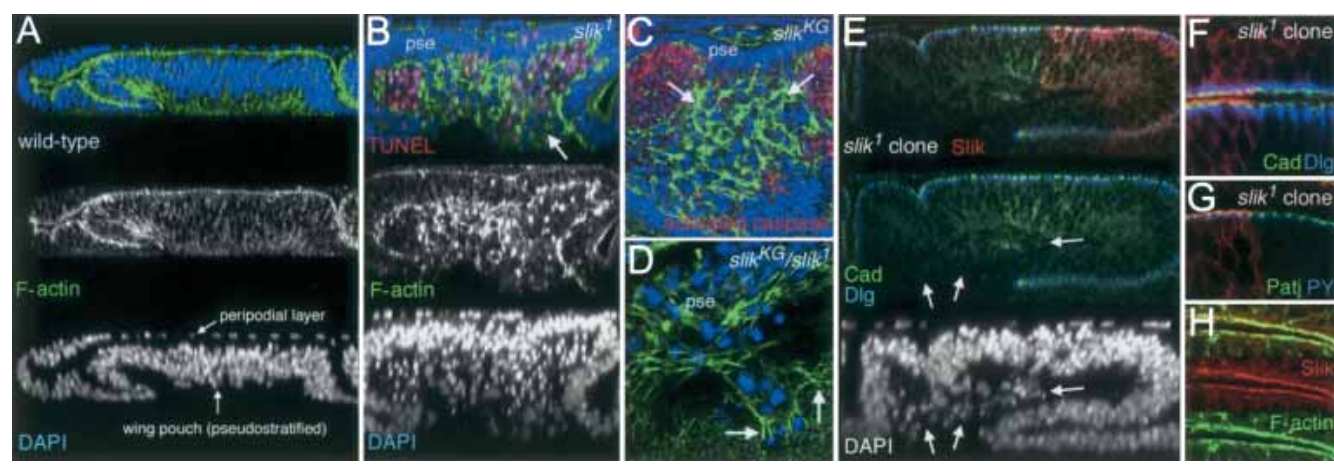

Figure 1. Epithelial integrity defects in Slik mutants. (A) Optical cross-section of a wild-type wing imaginal disc showing the presumptive wing, labeled to visualize F-actin (green) and nuclei (DAPI, blue). Note the multilayered nuclei in the pseudostratified wing pouch area, and the transition from columnar to squamous epithelial organization in the overlying peripodial layer. F-actin is enriched at the apical junctional complexes. (B) Optical cross-section of a slik ${ }^{1}$ homozygous null mutant wing disc. Apoptotic cells were labeled by TUNEL (red). The pseudostratified epithelium (pse) is abnormally thin. The space beneath the basal surface of the disc is full of extruded cells; many are TUNELpositive with pyknotic nuclei. Clusters of TUNEL-negative live cells are also extruded (arrow). Note also a few apoptotic cells in the epithelial layer. $(C, D)$ Horizontal optical sections taken just below the wing pouch epithelium of $s_{1 i k}{ }^{K G 4837}$ hypomorphic mutant and slik ${ }^{K G 4837} /$ slik $^{1}$ mutant discs. Apoptotic cells are labeled with antibody to activated caspase 3 (red in $C$ ). slik mutant cells with abnormally high levels of F-actin (arrows in C) lose their epithelial character and are extruded from the basal surface of the epithelium (pse, viewed in cross-section). Arrows in $D$ indicate F-actin-rich filopodia-like extensions in a cluster of cells migrating out of the epithelium (pse). (E-G) Cross-sections through wing disc epithelia with large clones of $\operatorname{slik}^{1}$ mutant cells. Slik protein (red) is absent from the clones. (E, $\left.F\right)$ E-Cadherin (green) and Discs large protein (blue) are localized normally in mutant cells in the epithelium, but are not localized in extruded cells (arrows in $E$ ). (F) Slik is apical to E-Cadherin and Discs large. $(G)$ Slik is apical to the Pati protein (green) and to adherens junctions labeled by concentrated Phosphotyrosine (blue). (H) Slik and F-actin colocalize apically in wild-type cells in an optical section that crosses a fold in the disc.

row). A similar but milder defect was seen in discs with reduced Slik activity. Many apoptotic cells with activated Caspase were seen in optical sections below the epithelial layer (Fig. 1C). Some of the extruded slik mutant cells were alive and appeared mesenchymal, having lost their polarized epithelial character (Fig. 1C,D). These cells produced F-actin-rich filopodia and appeared to acquire motile behavior (Fig. 1D, arrow). Thus slik activity helps cells to maintain epithelial integrity.

The observation that many live slik mutant cells were extruded from the epithelium suggested that loss of epithelial integrity was not a consequence of apoptosis. This was confirmed by producing clones of slik mutant cells that expressed the baculovirus caspase inhibitor p35. p35-expressing slik mutant cells also lost epithelial integrity and were extruded from the epithelium, but remained alive (data not shown). This suggests that apoptosis is a consequence of the loss of epithelial organization, perhaps due to loss of survival signaling by Raf (Hipfner and Cohen 2003).

To investigate whether slik is essential for epithelial polarity per se, we compared the subcellular localization of junctional complex proteins in normal cells and clones of slik ${ }^{1}$ null mutant cells. In wild-type cells, Slik protein was concentrated apically and colocalized with cortical actin, in addition to a diffuse cytoplasmic staining (Fig. 1E-H). Slik was concentrated apical to septate junctions (marked by Discs large) and adherens junctions (marked by E-Cadherin and anti-phosphotyrosine) and to the apical-most marginal zone complexes containing the PDZ-domain protein Patj, indicating that Slik is at or near the apical membrane rather than in the junctions. Junctional complexes appeared normal in slik mutant cells that remained in the disc epithelium, but were lacking in mutant cells that had left the epithelium (Fig. $1 \mathrm{E}$, arrows). Thus, although it is not essential for apicalbasal polarity, slik contributes to maintaining epithelial organization. Cells lacking slik often lose epithelial po- larity and leave the epithelium. Many of these cells undergo apoptosis.

\section{Defects in differentiation of microvilli-based structures}

slik ${ }^{1}$ mutant clones generated in the eye disc early in development and provided with a growth advantage can grow to large sizes. As in the wing disc, many cells were extruded from the eye disc and underwent apoptosis, whereas others remained integrated in the epithelium and showed normal expression of the neuronal marker ELAV in photoreceptors (data not shown). Adult eyes with large slik ${ }^{1}$ mutant clones showed moderate external roughness. Although we found many properly organized ommatidial clusters in these eyes, mutant photoreceptors showed defects during subsequent differentiation. Each photoreceptor normally projects a stack of actin-based microvilli, or rhabdomere, from the apical membrane domain that provides the increased membrane surface for harvesting light. Rhabdomeres form during pupal development (PD; Kumar and Ready 1995). By $70 \%$ PD, the eight photoreceptors that comprise a single facet in the wild-type eye have begun to form rhabdomeres consisting of short bundles of microvilli (Fig. 2A, arrows; note that only seven photoreceptors are visible in a section). The cells are connected to each other by adherens junctions, which separate the apical from the basolateral membrane domains (Fig. 2A, circle). At $95 \%$ PD the microvilli have extended to form regular bundles (Fig. 2B). The arrangement of photoreceptors was largely normal in complete ommatidia containing slik mutant clones, but many slik mutant photoreceptors had patches of apical membrane devoid of microvilli (Fig. 2C, arrows). Where present, the microvilli in slik mutant photoreceptors did not form organized stacks (Fig. 2C,D). Mutant photoreceptors were present in eyes 


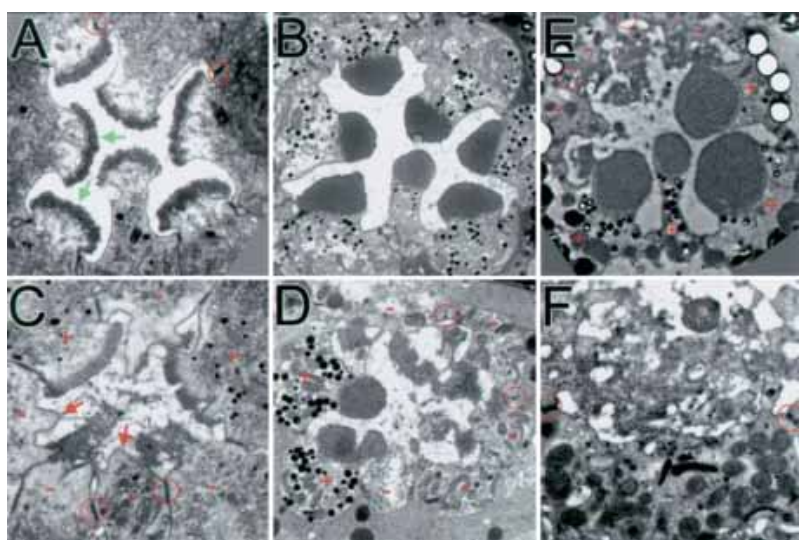

Figure 2. Defects in rhabdomere differentiation in slik mutant photoreceptors. $(A, B)$ Transmission electron microscopy (TEM) sections of single wild-type ommatidia. (A) $70 \%$ PD. Some adherens junctions are indicated (red circles). Green arrows indicate forming microvilli arrays. (B) 95\% PD. (C-F) Ommatidia with slik ${ }^{1}$ mutant clones. Wild-type cells have pigment granules (+). (-) Mutant cells; (red arrows) apical membranes lacking microvilli. (C) $70 \%$ PD (D) $95 \%$ PD. $(E, F)$ 18-day-old adult. $(F)$ Detail of the disorganized microvilli.

from 18-day-old adult flies, indicating that their survival as postmitotic cells was not impaired (Fig. 2E,F). These defects resemble those described recently in photoreceptors lacking Moesin (Karagiosis and Ready 2004).

\section{Slik acts via Moesin}

The similarity in slik and moesin mutant phenotypes prompted us to compare the defects in imaginal discs in more detail. Loss of Moesin causes defects in epithelial integrity due to Rhol-induced changes in the actin cytoskeleton (Speck et al. 2003). Interestingly, we found that cells extruded from moesin mutant discs also underwent massive apoptosis (Supplementary Fig. S1A,B). The organizational changes in the actin cytoskeleton were strikingly similar in the two genotypes. These defects in moesin mutant discs can be rescued by reduction of rho1 gene dosage (Speck et al. 2003). Similarly, the defects in epithelial integrity and cell survival in hypomorphic slik mutants were strongly suppressed when rho1 gene dosage was reduced (Supplementary Fig. S1C,D), suggesting that some defects in slik mutants are due to excessive Rhol activity and that Slik acts in the same pathway as Moesin.

Moesin is activated by phosphorylation on a conserved Threonine residue in the C-terminal domain. Thr 556-phosphorylated Moesin (P-Moesin) colocalized with apical Slik protein in wildtype cells (Fig. 3B, arrowhead), in addition to a diffuse distribution of both proteins. P-Moesin levels were considerably reduced in slik ${ }^{1}$ clones, compared to adjacent Slik-expressing cells in the wing disc (Fig. 3A,B). Immunoblot analysis showed that Thr 556-phosphorylation was reduced in slik mutant wing discs, as the level of total Moesin was unchanged (Fig. 3C). Likewise, Slik RNAi in S2 cells resulted in a dose-dependent decrease in endogenous Slik protein and in Moesin phosphorylation (Fig. 3D). Expression of
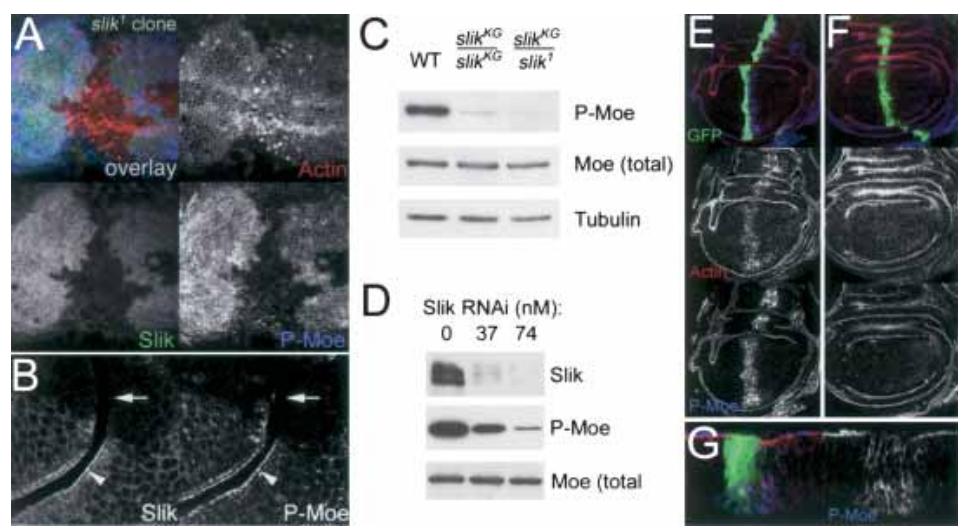

Figure 3. Slik kinase is required for regulatory phosphorylation of Moesin. $|A|$ Projection of a series of optical sections through the apical region of a wing disc with a large $\operatorname{slik}^{1}$ mutant clone. Thr 556-phosphorylated Moesin (P-Moe) was detected with a phospho-specific antibody (Polesello et al. 2002). P-Moe (blue) is reduced in cells lacking Slik protein (green). F-actin is shown in red. (B) An optical section through another clone crossing a fold shows two cell layers with their apical surfaces apposed. Slik and P-Moesin colocalize apically in wild-type cells (arrowheads), but are absent in slik mutant cells (arrows). (C) Immunoblot of extracts from wild-type (WT), homozygous slik ${ }^{K G 4837}$, and slik $^{K G 4837} /$ slik $^{1}$ mutant wing discs. $(D)$ Immunoblot of extracts from S2 cells treated with increasing concentrations of double-stranded RNA for Slik. $(E-G)$ Wing discs expressing GFP (green) and wild-type $(E, G)$ or catalytically inactive $(F)$ forms of the Slik kinase domain under ptc ${ }^{\text {Gala }}$ control and labeled for F-actin (red) and PMoesin (blue). $(G)$ Cross-section of the disc in $E$. The Slik kinase domain is not apically localized and causes relocalization of P-Moesin from the apical surface. 

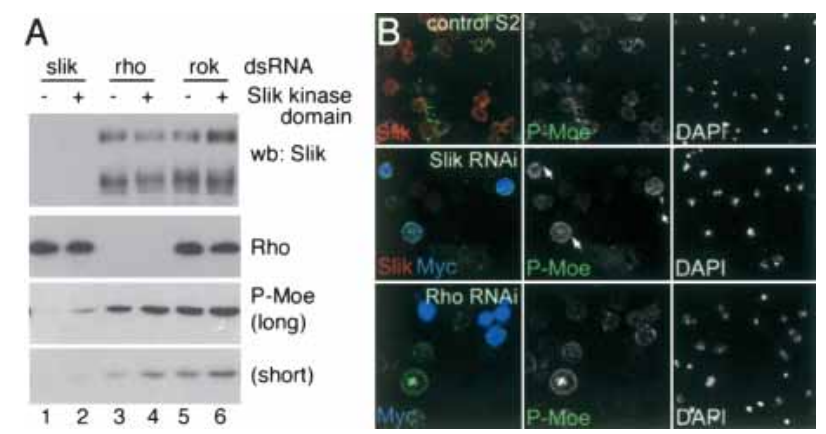

Figure 4. Role of Rho and Slik in Moesin phosphorylation. (A) Immunoblots of lysates from S2 cells treated with double-stranded RNA for Slik, Rho, or Rok. (+) Cells transfected to express the Slik kinase domain. (Upper panel) Slik protein was depleted by RNAi. The transfected kinase domain is not detected by the Slik antibody. (Second panel) Rho protein was depleted by RNAi. (Lower two panels) Long and short exposures of immunoblots showing levels of P-Moesin. (B) S2 cells labeled with anti-Slik (red), anti-P-Moe (green), and anti-Myc to visualize the transfected Myc-tagged Slik kinase domain (blue). Nuclei labeled with DAPI are shown at right. (Upper panels) Control S2 cells. (Middle panels) Cells treated with Slik dsRNA. Slik and P-Moe levels were strongly reduced. Few untransfected cells had high levels of P-Moe, but cells expressing the Slik kinase domain did (arrows). (Lower panels) Cells treated with Rho dsRNA. P-Moe levels were comparable to wild-type cells.

Moesin in S2 cells. The mammalian kinase Rock has been suggested to serve as an effector of Rho in mediating ERM protein phosphorylation, though this is controversial (Matsui et al. 1998, 1999; Oshiro et al. 1998; Tran Quang et al. 2000). Here, depletion of the Drosophila ortholog, Rok, from S2 cells had little or no effect on the level of Moesin phosphorylation, and did not prevent Slik kinase domain-induced Moesin phosphorylation (Fig. 4A, lanes 5,6). These observations suggest that Rhol is not required for Moesin phosphorylation in S2 cells. Although the level of Rho activity is elevated in slik mutants (Supplementary Fig. S1), the level of Moesin phosphorylation is very low (Fig. 3), suggesting that Rho activity cannot compensate for the lack of Slik activity.

\section{Partial rescue of slik mutants by activated Moesin}

We next asked whether the epithelial defects in slik mutants could be rescued by expression of a constitutively active, phosphomimetic form of Moesin (Moesin ${ }^{\mathrm{TD}}$; Speck et al. 2003). moe $e^{G O 323}$ mutants served as a control. Moesin protein was nearly undetectable in moe $e^{G 0323}$ discs by immunoblot (Fig. 5B). In mое arm $^{\text {GAL4 }}$ drove ubiquitous Moesin ${ }^{\mathrm{TD}}$ expression to a level lower than endogenous Moesin. This level of activated Moesin had no effect on the development of wildtype animals. moe ${ }^{G O 323}$ mutants grew more slowly than wild-type larvae, reached pupal stages later, and died as pupae (Fig. 5A). More than half of the mutant larvae were rescued to pharate adult $(25 \%)$ or adult stages $(28 \%)$ by expression of Moesin ${ }^{\mathrm{TD}}$ (vs. $0 \%$ and $1 \%$ for $\mathrm{moe}^{\mathrm{GO}} \mathrm{O} 23$ ). Moesin $^{\text {TD }}$ expression also partially rescued slik ${ }^{1}$ mutants. Nearly half of the slik ${ }^{1}$ animals survived to pupation, but all died shortly thereafter. In contrast, $9 \%$ of slik $^{1}$ mutants expressing Moesin ${ }^{\mathrm{TD}}$ reached the pharate adult stage (Fig. 5A,C). One small rescued slik ${ }^{1}$ mutant fly survived to adulthood (Fig. 5D). Discs from rescued slik $^{1}$ mutants showed some improvement in overall structure and actin organization. Basal extrusion of cells was reduced and in some cases nearly eliminated (Fig. 5E).

\section{Slik-driven growth is independent of Moesin regulation}

Moesin ${ }^{\text {TD }}$ expression did not rescue $s{ }^{1} k^{1}$ animals to the same extent as moe $\mathrm{GO}^{\mathrm{G} 3}$ mutants. Despite improvements in epithelial integrity and the stage of lethality, Moesin $^{\text {TD }}$ had little or no effect on the slow rate of development and growth of slik ${ }^{1}$ mutants (Fig. 5A). One explanation for this may be that Moesin acts downstream of Slik to regulate epithelial integrity but not to promote growth. We tested this by examining the requirement for Moesin in Slik-driven tissue growth. The effect of Slik on cell proliferation is easily observed in the peripodial cells overlying the columnar wing disc epithelium (Supplementary Fig. S2). Expression of Slik in the columnar epithelium induced nonautonomous proliferation of peripodial cells, detectable as an increase in nuclear density and BrdU incorporation. The same effect was observed when Slik was expressed in moe $e^{G 0323} \mathrm{mu}-$ tants. Activated Moesin ${ }^{\mathrm{TD}}$ did not affect cell proliferation. Thus Moesin is not necessary for Slik-induced cell proliferation, nor is Moesin activity sufficient to stimulate cell proliferation.

We conclude that Slik regulates epithelial integrity via Moesin activation, independent of its effects on tissue growth. Slik-induced tissue growth is Raf-dependent. Expression of a kinase inactive form of Slik is capable of promoting Raf-dependent overproliferation, suggesting that the growth effect may be mediated by protein-protein interactions rather than by Slik kinase activity (Hipfner and Cohen 2003). Consistent with this notion, expression of the kinase domain of Slik alone did not induce cell proliferation or tissue overgrowth. In contrast, Moesin phosphorylation is dependent on Slik kinase activity. Taken together, these observations suggest two distinct effector pathways for Slik-a pathway controlling growth, involving Raf, and a separate pathway controlling epithelial integrity involving Moesin phosphorylation.

What might be the purpose of the dual activities of Slik? Slik is not essential for cells to grow and divide, but it does control the rate of cell proliferation. Slik activity must be maintained within a defined range; too much or too little activity results in apoptosis (Hipfner and Cohen 2003). Mitogenic signaling through Slik could promote tissue growth and at the same time reinforce cellular architecture by maintaining Moesin in an active state. Proliferation-induced apoptosis prevents excessive Slik signaling from deregulating proliferation, as has been suggested for certain oncogenes (Evan and Littlewood 1998; Hipfner and Cohen 2003). Under conditions of reduced mitogenic signaling, decreased Slik activity would result in a lower rate of cell proliferation and, by reducing Moesin activity, make cells more likely to be extruded from the disc and thus to undergo apoptosis. A more direct function of ERM proteins in regulating apoptosis may also be involved (Gautreau et al. 1999; Parlato et al. 2000). Thus, Slik activity may serve as a switch between pro-proliferative and pro-apoptotic states. Consistent with this idea, loss of ERM protein phosphorylation and activity has been shown to be an early event in apoptosis (Kondo et al. 1997). Interestingly, it is known 

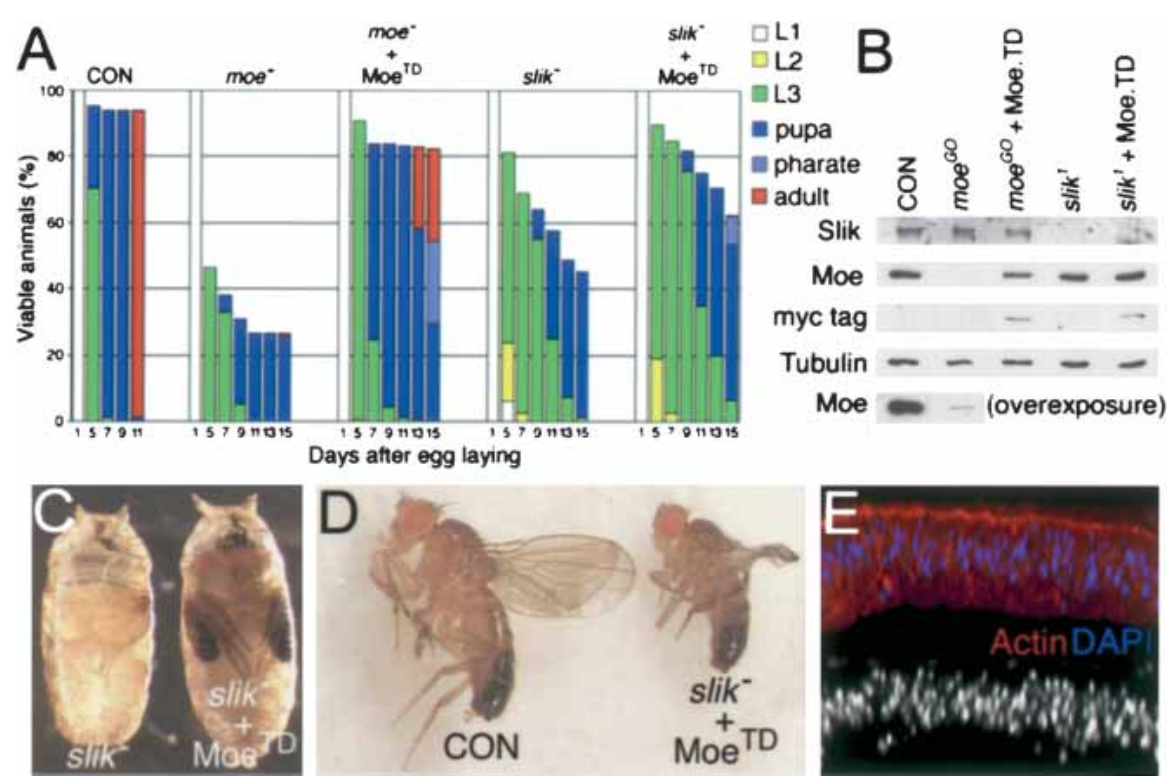

Figure 5. Partial rescue of slik mutants by activated Moesin. (A) Histograms showing the proportion of animals at different larval, pupal, and adult stages as a function of age. $\left(\mathrm{moe}^{-}\right) \mathrm{moe}^{\mathrm{GO}}{ }^{23} / \mathrm{Y}$ mutant; $\left(\mathrm{Moe}^{\mathrm{TD}}\right)$ Myc-epitope tagged Thr 556 Asp phosphomimetic form of Moesin; (slik $\left.{ }^{-}\right)$ slik $^{1} /$ slik $^{1}$. Numbers of larvae: CON, $n=80 ; \mathrm{moe}^{-}, n=97 ; \mathrm{moe}^{-}+\mathrm{Moe}^{\mathrm{TD}}, n=191$; slik,$n=80$; slik $^{-}+$Moe $^{\mathrm{TD}}, n=280$. (B) Immunoblots of imaginal disc lysates as in $A .(C) s^{\prime i k}{ }^{1}$ mutant pupa and $\operatorname{sik}^{1}$ arm $^{G A L 4} U A S-M o e^{T D}$ mutant rescued to pharate adult stage. Eyes (orange), wings (black), and legs are seen. (D) A rare adult survivor (1/280) of the rescued genotype. (E) Optical cross-section of a slik ${ }^{1} \operatorname{arm}^{G A L A} U A S-M o e^{T D}$ wing disc.

that slowly dividing cells in Drosophila imaginal discs undergo apoptosis as a result of reduced ability to compete for survival factors (Moreno et al. 2002). The dual activity of Slik may help to ensure elimination of less fit cells.

\section{Materials and methods}

Fly strains and reagents

$\operatorname{slik}^{1}$ is a null allele that removes the kinase domain; $\operatorname{slik}^{K G 4837}$ is a hypomorphic allele as described in Hipfner and Cohen (2003). rho1 ${ }^{72 O}$ was from M. Mlodzik (Mount Sinai School of Medicine, New York, NY). moe $e^{G O 323}$ (Bloomington Stock Center) is caused by a P-element insertion that strongly reduces Moesin protein levels, but must be considered hypomorphic because some Moesin is detectable on immunoblots. UASMoe $^{\mathrm{TD}}$ was from R. Fehon (Duke University, Durham, NC; Speck et al. 2003). Antibodies used were as follows: rabbit anti-Moesin (D. Kiehart, Duke University, Durham, NC); rabbit anti-Patj (H. Bellen, Baylor College of Medicine, Houston, TX); rat anti-E-Cadherin (M. Takeichi, Kyoto University, Kyoto, Japan); mouse anti-Discs Large, mouse anti-Rho (Developmental Studies Hybridoma Bank), rabbit anti-cleaved human caspase 3, and rabbit anti-human phospho-ERM antibodies (Cell Signalling Technology); mouse anti-phosphotyrosine (Upstate); and mouse anti-tubulin (Sigma). UAS-slik kin and UAS-slik kin.kd encoding Slik amino acids 1-322 were generated by amplification of wild-type or kinase-inactive mutant (Asp 176 to Phe) slik cDNAs (Hipfner and Cohen 2003). For analysis of slik imaginal discs, w; FRT42D, slik ${ }^{1} / \mathrm{CyO} \mathrm{Kr}^{\mathrm{GAL} 4}$ UAS-GFP and $\mathrm{W}$; slik ${ }^{K G 4837} / \mathrm{CyO} \mathrm{Kr}^{G A L 4} U A S$-GFP stocks were used and GFP-negative larvae dissected. Rescue tests were as follows: moe $^{G 0323 /}$ FM7 $\mathrm{Kr}^{G A L 4} U A S-G F P$ virgins were crossed to $\mathrm{w} / \mathrm{Y}$ or $\mathrm{w} / \mathrm{Y}$; $\mathrm{arm}^{\mathrm{GAL} 4}$ $U A S-M o e^{T D} / C y O K^{G A L 4} U A S-G F P$ males. GFP-negative larvae were collected. Only males had the correct genotype. W; arm ${ }^{G A L 4}$, slik ${ }^{1} / C y O$

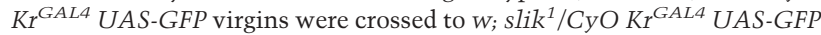
or $w$; UAS-Moe $e^{T D}$, slik $1 / C y O K r^{G A L 4} U A S$-GFP males. GFP-negative larvae were analyzed. $w^{1118}$ and $a r m^{G A L 4} U A S-M o e^{T D}$ larvae were used as controls. Collections and analysis of larvae, TUNEL, BrdU, and antibody labeling were performed as described (Hipfner and Cohen 2003).

Genotypes of larvae for generation of mosaic clones y, w, ey-FLP, P\{GMR-LacZ\}; FRT42D, P\{w+\}, 1(2)cl-R11/FRT42D, slik ${ }^{1}$ (for eye clones).

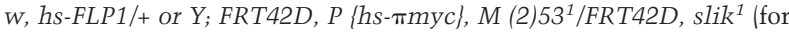
wing clones). Larvae were heat shocked at $36 \mathrm{~h} \pm 12 \mathrm{~h}$ for $40 \mathrm{~min}$ at $37.5^{\circ} \mathrm{C}$ and dissected after $\sim 5 \mathrm{~d}$.

Imaginal disc extracts

Ten wing/haltere/leg disc complexes were solubilized in $50 \mu \mathrm{L}$ of lysis buffer (50 mM Tris at pH 7.5, $150 \mathrm{mM} \mathrm{NaCl}, 1 \%$ Triton X-100 containing $30 \mathrm{mM} \mathrm{NaF}$ and $1 \times$ protease inhibitor cocktail, Roche).

$R N A$ interference in $S 2$ cells

Double-stranded RNA was prepared using the following templates: nucleotides 1529-2043 of the coding sequence in Slik CG4527; nucleotides 273-851 of rho1-RA; and nucleotides 2787-3293 of rok-RA. For RNAi, $4 \times 10^{6} \mathrm{~S} 2$ cells in $1 \mathrm{~mL}$ Drosophila serum-free medium supplemented with $16.5 \mathrm{nM}$ L-glutamine (Invitrogen) were plated per well in six-well plates. dsRNA was added to 37 or $74 \mathrm{nM}$ concentration. After 30 min, $2 \mathrm{~mL}$ medium was added. Cells were harvested $3 \mathrm{~d}$ later. For RNAi and transfection, $2 \times 10^{6} \mathrm{~S} 2$ cells per well were treated with $12 \mu \mathrm{g}$ of dsRNA. Two days later, cells were transfected with $2 \mu \mathrm{g}$ of pMT-Gal4 and $2 \mu \mathrm{g}$ of $p U A S T$ or $p U A S T$-slik ${ }^{k i n}$. After $12 \mathrm{~h}$, the mixture was replaced with medium containing $20 \mu \mathrm{g}$ of dsRNA. Cells were induced 12 h later by addition of $0.7 \mathrm{mM} \mathrm{CuSO}_{4}$.

Electron microscopy

Bisected heads were fixed for $15 \mathrm{~min}$ in ice-cold $2 \%$ glutaraldehyde, 0.1 $\mathrm{M}$ sodium phosphate at $\mathrm{pH} 7.2$. One volume of $2 \% \mathrm{OsO}_{4}$ in $0.1 \mathrm{M}$ sodium phosphate at $\mathrm{pH} 7.2$ was added for $1 \mathrm{~h}$. Samples were incubated for $4 \mathrm{~h}$ on ice in fresh $\mathrm{OsO}_{4}$ solution, dehydrated by successive incubations in an ethanol series $(30 \%, 50 \%, 70 \%, 80 \%, 90 \%, 100 \%, 100 \%)$, followed by two 10-min washes in propylene oxide. Heads were equilibrated overnight in a 1:1 mixture of polypropylene oxide and Durcupan resin (Fluka), transferred into $100 \%$ resin, and incubated at least $6 \mathrm{~h}$ at $20^{\circ} \mathrm{C}$. Heads were transferred into molds containing fresh resin and baked overnight at $70^{\circ} \mathrm{C}$. Ultrathin-sections were cut and poststained with $2 \%$ uranyl acetate.

\section{Acknowledgments}

We thank Don Ready for advice and Sigrun Brendl and Ken Goldie for assistance with TEM. 


\section{References}

Bilder, D., Li, M., and Perrimon, N. 2000. Cooperative regulation of cell polarity and growth by Drosophila tumor suppressors. Science 289: $113-116$.

Dan, I., Watanabe, N.M., and Kusumi, A. 2001. The Ste20 group kinases as regulators of MAP kinase cascades. Trends Cell Biol. 11: 220-230.

Denker, S.P., Huang, D.C., Orlowski, J., Furthmayr, H., and Barber, D.L. 2000. Direct binding of the Na-H exchanger NHE1 to ERM proteins regulates the cortical cytoskeleton and cell shape independently of $\mathrm{H}(+)$ translocation. Mol. Cell 6: 1425-1436.

Doi, Y., Itoh, M., Yonemura, S., Ishihara, S., Takano, H., Noda, T., and Tsukita, S. 1999. Normal development of mice and unimpaired cell adhesion/cell motility/actin-based cytoskeleton without compensatory up-regulation of ezrin or radixin in moesin gene knockout. J. Biol. Chem. 274: 2315-2321.

Evan, G. and Littlewood, T. 1998. A matter of life and cell death. Science 281: $1317-1322$.

Gary, R. and Bretscher, A. 1995. Ezrin self-association involves binding of an $\mathrm{N}$-terminal domain to a normally masked C-terminal domain that includes the F-actin binding site. Mol. Biol. Cell 6: 1061-1075.

Gateff, E. 1978. Malignant neoplasms of genetic origin in Drosophila melanogaster. Science 200: 1448-1459.

Gautreau, A., Poullet, P., Louvard, D., and Arpin, M. 1999. Ezrin, a plasma membrane-microfilament linker, signals cell survival through the phosphatidylinositol 3-kinase/Akt pathway. Proc. Natl. Acad. Sci. 96: 7300-7305.

Harvey, K.F., Pfleger, C.M., and Hariharan, I.K. 2003. The Drosophila Mst ortholog, hippo, restricts growth and cell proliferation and promotes apoptosis. Cell 114: 457-467.

Heiska, L., Alfthan, K., Gronholm, M., Vilja, P., Vaheri, A., and Carpen, O. 1998. Association of ezrin with intercellular adhesion molecule-1 and -2 (ICAM-1 and ICAM-2). Regulation by phosphatidylinositol 4, 5-bisphosphate. J. Biol. Chem. 273: 21893-21900.

Hipfner, D.R. and Cohen, S.M. 2003. The Drosophila Sterile-20 kinase Slik controls cell proliferation and apoptosis during imaginal disc development. PLOS. Biol. 1: 244-256.

Huang, S. and Ingber, D.E. 1999. The structural and mechanical complexity of cell-growth control. Nat. Cell Biol. 1: E131-E138.

Humbert, P., Russell, S., and Richardson, H. 2003. Dlg, Scribble and Lgl in cell polarity, cell proliferation and cancer. Bioessays 25: 542-553.

Karagiosis, S.A. and Ready, D.F. 2004. Moesin contributes an essential structural role in Drosophila photoreceptor morphogenesis. Development 131: 725-732.

Kondo, T., Takeuchi, K., Doi, Y., Yonemura, S., Nagata, S., and Tsukita, S. 1997. ERM (ezrin/radixin/moesin)-based molecular mechanism of microvillar breakdown at an early stage of apoptosis. J. Cell Biol. 139: 749-758.

Kumar, J.P. and D.F. Ready. 1995. Rhodopsin plays an essential structural role in Drosophila photoreceptor development. Development 121: 4359-4370.

Lozano, E., Betson, M., and Braga, V.M. 2003. Tumor progression: Small GTPases and loss of cell-cell adhesion. Bioessays 25: 452-463.

Matsui, T., Maeda, M., Doi, Y., Yonemura, S., Amano, M., Kaibuchi, K., and Tsukita, S. 1998. Rho-kinase phosphorylates COOH-terminal threonines of ezrin/radixin/moesin (ERM) proteins and regulates their head-to-tail association. J. Cell. Biol. 140: 647-657.

Matsui, T., Yonemura, S., and Tsukita, S. 1999. Activation of ERM proteins in vivo by Rho involves phosphatidyl-inositol 4-phosphate 5-kinase and not ROCK kinases. Curr. Biol. 9: 1259-1262.

Moreno, E., Basler, K., and Morata, G. 2002. Cells compete for decapentaplegic survival factor to prevent apoptosis in Drosophila wing development. Nature 416: 755-759.

Oshiro, N., Fukata, Y., and Kaibuchi, K. 1998. Phosphorylation of moesin by rho-associated kinase (Rho-kinase) plays a crucial role in the formation of microvilli-like structures. J. Biol. Chem. 273: 3466334666.

Pantalacci, S., Tapon, N., and Leopold, P. 2003. The Salvador partner Hippo promotes apoptosis and cell-cycle exit in Drosophila. Nat. Cell Biol. 5: 921-927.

Parlato, S., Giammarioli, A.M., Logozzi, M., Lozupone, F., Matarrese, P., Luciani, F., Falchi, M., Malorni, W., and Fais, S. 2000. CD95 (APO$1 / \mathrm{Fas})$ linkage to the actin cytoskeleton through ezrin in human $\mathrm{T}$ lymphocytes: A novel regulatory mechanism of the CD95 apoptotic pathway. EMBO J. 19: 5123-5134.

Polesello, C., Delon, I., Valenti, P., Ferrer, P., and Payre, F. 2002. Dmoesin controls actin-based cell shape and polarity during Drosophila melanogaster oogenesis. Nat. Cell Biol. 4: 782-789.

Reczek, D. and Bretscher, A. 1998. The carboxyl-terminal region of EBP50 binds to a site in the amino-terminal domain of ezrin that is masked in the dormant molecule. J. Biol. Chem. 273: 18452-18458.

Serrador, J.M., Alonso-Lebrero, J.L., del Pozo, M.A., Furthmayr, H., Schwartz-Albiez, R., Calvo, J., Lozano, F., and Sanchez-Madrid, F. 1997. Moesin interacts with the cytoplasmic region of intercellular adhesion molecule- 3 and is redistributed to the uropod of T lymphocytes during cell polarization. J. Cell Biol. 138: 1409-1423.

Shaw, R.J., Henry, M., Solomon, F., and Jacks, T. 1998. RhoA-dependent phosphorylation and relocalization of ERM proteins into apical membrane/actin protrusions in fibroblasts. Mol. Biol. Cell 9: 403-419.

Speck, O., Hughes, S.C., Noren, N.K., Kulikauskas, R.M., and Fehon, R.G. 2003. Moesin functions antagonistically to the Rho pathway to maintain epithelial integrity. Nature 421: 83-87.

Takeuchi, K., Sato, N., Kasahara, H., Funayama, N., Nagafuchi, A., Yonemura, S., and Tsukita, S. 1994. Perturbation of cell adhesion and microvilli formation by antisense oligonucleotides to ERM family members. J. Cell Biol. 125: 1371-1384.

Tran Quang, C., Gautreau, A., Arpin, M., and Treisman, R. 2000. Ezrin function is required for ROCK-mediated fibroblast transformation by the Net and Dbl oncogenes. EMBO I. 19: 4565-4576.

Turunen, O., Wahlstrom, T., and Vaheri, A. 1994. Ezrin has a COOHterminal actin-binding site that is conserved in the ezrin protein family. J. Cell Biol. 126: 1445-1453.

Udan, R.S., Kango-Singh, M., Nolo, R., Tao, C., and Halder, G. 2003. Hippo promotes proliferation arrest and apoptosis in the Salvador/ Warts pathway. Nat. Cell Biol. 5: 914-920.

Woods, D.F. and Bryant, P.J. 1989. Molecular cloning of the lethal(1)discs large-1 oncogene of Drosophila. Dev. Biol. 134: 222-235.

Wu, S., Huang, J., Dong, J., and Pan, D. 2003. hippo encodes a Ste-20 family protein kinase that restricts cell proliferation and promotes apoptosis in conjunction with salvador and warts. Cell 114: 445-456.

Yonemura, S., Hirao, M., Doi, Y., Takahashi, N., Kondo, T., and Tsukita, S. 1998. Ezrin/radixin/moesin (ERM) proteins bind to a positively charged amino acid cluster in the juxta-membrane cytoplasmic domain of CD44, CD43, and ICAM-2. J. Cell Biol. 140: 885-895.

Yun, C.H., Lamprecht, G., Forster, D.V., and Sidor, A. 1998. NHE3 kinase A regulatory protein E3KARP binds the epithelial brush border $\mathrm{Na}+$ / $\mathrm{H}+$ exchanger NHE3 and the cytoskeletal protein ezrin. J. Biol. Chem. 273: 25856-25863.

Zahir, N. and Weaver, V.M. 2004. Death in the third dimension: Apoptosis regulation and tissue architecture. Curr. Opin. Gen. Dev. 14: $1-10$. 


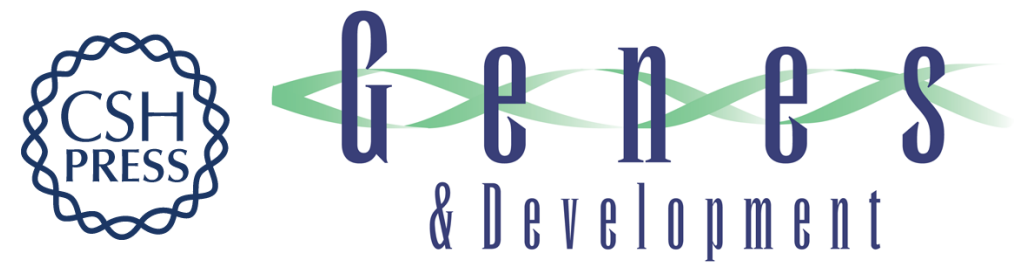

\section{Slik Sterile-20 kinase regulates Moesin activity to promote epithelial integrity during tissue growth}

David R. Hipfner, Nadine Keller and Stephen M. Cohen

Genes Dev. 2004, 18:

Access the most recent version at doi:10.1101/gad.303304

Supplemental http://genesdev.cshlp.org/content/suppl/2004/09/02/18.18.2243.DC1
Material

References This article cites 36 articles, 21 of which can be accessed free at: http://genesdev.cshlp.org/content/18/18/2243.full.html\#ref-list-1

License

Email Alerting

Receive free email alerts when new articles cite this article - sign up in the box at the top Service right corner of the article or click here.

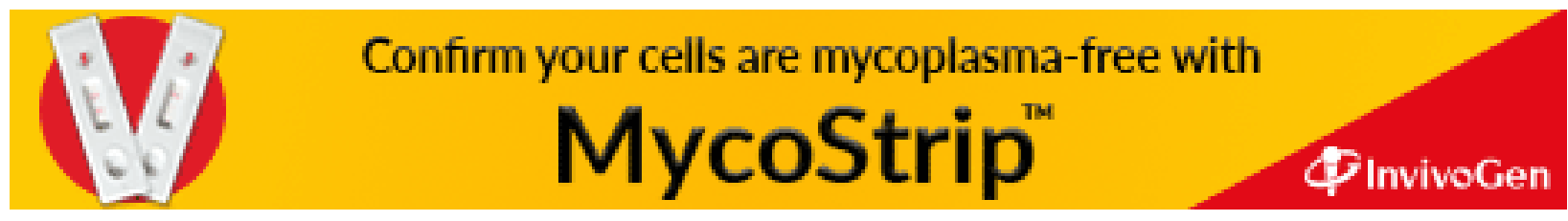

